\title{
Videomicroscopic Demonstration of Defective Cholinergic Arteriolar Vasodilation in Atherosclerotic Rabbit
}

\author{
Hideo Yamamoto, Claus Bossaller, Joiner Cartwright, Jr., and Philip D. Henry \\ Section of Cardiology, Department of Medicine, Baylor College of Medicine, Houston, Texas 77030; \\ and The Methodist Hospital, Houston, Texas 77030
}

\begin{abstract}
In atherosclerotic rabbits (SCLER), decreases in vascular resistance in response to acetylcholine (ACH), an endotheliumdependent agent, are suppressed, whereas those to nitroprusside (NP), an endothelium-independent vasodilator, are preserved. To determine whether defective vasodilation in SCLER is related to altered reactivity of resistance vessels, we visualized arterioles of rabbit cremaster muscle by videomicroscopy. Arteriolar diameter was monitored during topical (superfusional) delivery of $\mathrm{ACH}$ and NP, interventions that did not affect systemic hemodynamics. Diameter changes in response to NP (0.01-100.0 $\mu \mathrm{M})$ did not differ between SCLER and controls; maximal dilations amounted to $110 \pm 10 \%$ (mean \pm SE). In contrast, responses to $\mathrm{ACH}(0.001-100 \mu \mathrm{M})$ differed; maximal dilations averaged $54 \pm 4 \%$ in SCLER and $124 \pm 9 \%$ in controls $(P<0.001)$. These differences persisted after blockade with phentolamine, propranol, and indomethacin. Phenidone and hydroquinone blockers of endothelium-dependent vasodilation, inhibited arteriolar dilation to $\mathbf{A C H}$ without affecting that to NP. Microvascular responses to intraarterial drug were similar to those elicited by topical drug. Thus, hypercholesterolemia and atherosclerosis in the rabbit appear to produce a microvascular defect characterized by an impaired endothelium-dependent dilation and a preserved endothelium-independent dilation. This defect could play a role in limiting vasodilator reserve in atherosclerosis.
\end{abstract}

\section{Introduction}

Although atherosclerotic lesions develop only in large arteries, it has not been established whether factors generating atheromas in large arteries may concomitantly produce functional or structural alterations of small arteries that are not manifested by the formation of atheromatous lesions. Endothelial injury has been invoked to play a key role in atherogenesis, and it has been pointed out that the "response-to-injury hypothesis" may entail endothelial alterations more subtle than atherosclerotic endothelial desquamation (1).

This paper was presented in part at the 36th Annual Scientific Session of the American College of Cardiology, New Orleans, and appeared in abstract form (1987. J. Am. Coll. Cardiol. 9:211A).

Address correspondence to Dr. Henry, Professor of Medicine, Section of Cardiology, Baylor College of Medicine, 6535 Fannin, Suite F-905, Houston, TX 77030.

Received for publication 22 June 1987 and in revised form 30 October 1987.

J. Clin. Invest.

(c) The American Society for Clinical Investigation, Inc.

0021-9738/88/06/1752/07 $\$ 2.00$

Volume 81, June 1988, 1752-1758
Recently, large atherosclerotic arteries from animals with experimental atherosclerosis and patients with coronary disease have been shown not to relax normally in response to vasodilators known to act indirectly on smooth muscle by stimulating the release of an endothelium-derived relaxing factor (EDRF) $)^{1}(2-4)$. In addition, we have demonstrated that in cholesterol-fed rabbits, EDRF-dependent vasodilators are ineffective in evoking a fall in the total vascular resistance of the hindlimb, whereas EDRF-independent agents remain potent (5). Since total vascular resistance is usually determined predominantly by small resistance vessels, we postulated that cholesterol-fed rabbits may have a defective endothelium-dependent relaxation affecting not only large but also small arteries or arterioles. The present study was designed to test this hypothesis by characterizing the reactivity of skeletal muscle arterioles in cholesterol-fed rabbits with the use of standard microcirculatory techniques.

\section{Methods}

Animals. 50 male New Zealand white rabbits from a single vendor (Rich-Glo, El Campo, TX) weighing 3.1 and $3.9 \mathrm{~kg}$ were housed individually in wire-bottom cages in an air-conditioned room at $20^{\circ} \mathrm{C}$ and $50 \%$ humidity with $12-\mathrm{h} / 12$-h light/dark cycle. The housing and experimental procedures were in accordance with the guide for care and use of laboratory animals issued by the U. S. Institute of Laboratory Animal Resources. After an adaptation period of $1 \mathrm{wk}$, the animals were separated into two equal groups which were randomly assigned to one of two dietary regimens: $(i)$ standard chow, and (ii) chow containing $1 \%$ cholesterol (both diets supplied by ICN Nutritional Biochemicals, Cleveland, $\mathrm{OH}$ ).

At the end of the dietary period (12 $\pm 1 \mathrm{wk})$ rabbits were anesthetized with pentobarbital ( $25 \mathrm{mg} / \mathrm{kg}$ i.v.), intubated and ventilated with a Harvard model 613 piston pump. The rectal temperature was maintained at $37^{\circ}-38^{\circ} \mathrm{C}$ with a heating pad. To monitor arterial pressure and heart rate, a catheter attached to a Statham $\mathrm{P} 23 \mathrm{~Gb}$ pressure transducer was inserted via the left carotid artery into the thoracic aorta. The transducer signals were amplified and recorded with a Gould transducer amplifier and 2200 S Gould recorder. For the intraarterial delivery of drug, the distal abdominal aorta was catheterized via the right femoral artery.

Venous blood samples were collected in $\mathrm{Na}_{2}$ EDTA tubes $(1 \mu \mathrm{g} / 100$ $\mu \mathrm{l})$ at the beginning of the operation for the determination of plasma cholesterol as previously described (6).

Open cremaster preparation. An open cremaster muscle preparation (7) was used to observe the microcirculation of a skeletal muscle in vivo. The rabbits were laid down on an adjustable platform, with the caudal end of the animal facing a microscope stage carrying a Plexiglas organ chamber. The trapezoid-shaped shallow chamber (height of walls, $0.7 \mathrm{~cm}$; lengths of long and short parallel walls, 7 and $3.5 \mathrm{~cm}$; capacity, $7 \mathrm{ml}$ ) was positioned between the thighs of the rabbit, and

1. Abbreviations used in this paper: $\mathrm{ACH}$, acetylcholine; $\mathrm{EDRF}$, endothelium-derived relaxing factor; EM, electron microscopy; NP, nitroprusside; SCLER, atherosclerotic rabbits. 
after opening of the scrotal sac, the left cremaster muscle and testicle were pulled into the chamber with the spermatic cord entering the bath through an indentation in the short parallel wall of the chamber. The cremaster muscle was opened, spread over the central portion of the chamber bottom, and the testicle was removed. All bleeding points were ligated carefully with $6-0$ silk. The muscle was attached under minimal stretch to the periphery of the chamber with pins inserted into silicon elastomer covering the peripheral chamber bottom. The chamber was perfused with warm $\left(35^{\circ} \mathrm{C}\right) \mathrm{Krebs}$ buffer containing (in millimolar) $\mathrm{NaCl}, 116 ; \mathrm{KCl}, 4 ; \mathrm{CaCl}_{2}, 1.5 ; \mathrm{MgSO}_{4}, 1.2 ; \mathrm{NaHPO}_{4}$, 1.2 ; and $\mathrm{NaHCO}_{3}, 25$. The superfusate entering the chamber had a pH of 7.40 and a $\mathrm{pO}_{2}$ of $<3 \mathrm{mmHg}$ achieved by equilibrating the buffer with a $95 \% \mathrm{~N}_{2}-5 \% \mathrm{CO}_{2}$ gas atmosphere. The buffer was pumped at a rate of $20 \mathrm{ml} / \mathrm{min}$ into one corner of the chamber, and continuously aspirated from above through a vertical tube at the opposite corner of the bath. The level of the tip of the tube determining the chamber's fluid level was adjusted so that the observed muscle was covered with a minimal fluid layer of $\sim 0.5 \mathrm{~mm}$. To prevent twitching of the muscle, the rabbits were given gallamine, $5 \mathrm{mg} / \mathrm{kg}$ i.v. (7).

In vivo microscopy. The modified microscope stage was part of a video-microscopic assembly composed of an Olympus microscope stand with trinocular tube, a long-working distance objective (Olympus $\times 40)$, a filar micrometric eyepiece $(\times 10)$, a Cohu 5172 television camera with Newvicon image tube, a video monitor, and video tape recorder (Panasonic models WV-5470 and AG6300). The muscle was transilluminated using a $20 \mathrm{~W}$ halogen lamp and a green filter (Olympus IF550). Arterioles were selected for observation on the basis of viewing clarity, size (third order arterioles with resting diameters ranging between 20 and $40 \mu \mathrm{m}$ ), and reactivity to topical (superfusional) administration of vasodilators (acetylcholine $[\mathrm{ACH}]$, nitroprusside [NP]). Care was taken to visualize the midplane of the vessel by bringing into focus the sharpest outer borders and widest image of the vessel. Arterioles exhibiting indistinct outer borders, sluggish flow, stasis of cells, extravasated red cells, and increases in diameter in response to $10 \mu \mathrm{M}$ NP of $<40 \%$ were excluded. If not otherwise specified, midplane transverse diameters were measured with a caliper accurate to the $0.01 \mathrm{~mm}$ directly applied to the video monitor screen at a total (optical plus electronic) magnification of $\sim 1,000$. Absolute calibration was obtained with a micrometer grid on the bottom of the optical window of the organ chamber. In some experiments, hard prints of the video recordings were obtained with a model UP-811 Sony video printer, and diameters were measured with the caliper on 15- $\times 15-\mathrm{cm}$ prints. In methodological experiments, measurements of microvessel diameters were performed independently by two observers and compared. They performed measurements by the video screen method ( $n=13$ different vessels) in random sequence nearly simultaneously, and took months' later measurements from the corresponding coded video-prints. Measurements by the video screen and video print methods averaged $25.5 \pm 1.6$ and $26 \pm 2.1 \mu \mathrm{m}$ for observer 1 , and $25.8 \pm 1.9$ and $24.9 \pm 2.5 \mu \mathrm{m}$ for observer 2 . None of the values were statistically significantly different by unpaired $t$ tests. With our system, measurements can be reproduced to within $\sim 0.5 \mu \mathrm{m}$ in agreement with resolutions reported by others (8).

Noninvasive ultrasound imaging of femoral artery. During intraaortic administration of drug we monitored simultaneously macrovascular and microvascular vasomotor effects. While observing microvessels of the cremaster muscle, we visualized the ipsilateral common femoral artery by high resolution ultrasound imaging using a Biosound Image processor (Surgiscan) equipped with a high frequency scanning probe (Surgiscan 2/12 probe). The transducer has a nominal mid-frequency of $12 \mathrm{MHz}$, a length and width of field of 2 and $1.3 \mathrm{~cm}$, and axial, lateral, and azimuthal resolutions of $\sim 0.1,0.3$, and 0.2 $\mathrm{mm}$. Care was taken to apply no pressure on the inguinal area which was covered with a commercial ultrasound gel. Analogue images in a 256-shade gray scale were displayed at $20 \times$ total magnification on a high resolution video monitor and recorded on tape as for the microvascular images. In this study, we have used only longitudinal views to take advantage of the superior axial resolution along the path of the sound beam. Longitudinal images exhibiting sharp intimal echo lines were analyzed on the video screen or on hard prints by the techniques used for the analysis of microscopic images of microvessels. Our diameter measurements based on longitudinal views have been previously validated in our laboratory by simultaneous arteriography over a range of artery diameters observed in this study (9).

\section{Protocol}

Drugs were administered by intraarterial infusion into the lower abdominal aorta or topically by superfusion of the cremaster muscle. Intraarterial infusions of $\mathrm{ACH}(0.14,0.4,1.2,3.0$, and 10.0 $\mu \mathrm{g} / \mathrm{kg} \cdot \mathrm{min})$ and sodium NP $(7.0,20.0,40.0$, and $80.0 \mu \mathrm{g} / \mathrm{kg} \cdot \mathrm{min})$ were administered continuously with a Harvard syringe infusion pump, with maximum flow rates of the infusate not exceeding 0.14 $\mathrm{ml} / \mathrm{min}$. Drugs and drug dosages were administered in randomized sequence, and in all experiments the person monitoring video-images did not know which of the vasodilators was administered. Changes in the diameter of the observed arteriole were monitored semicontinuously for $2 \mathrm{~min}$ before, $3 \mathrm{~min}$ during, and $5 \mathrm{~min}$ after drug administration. Infusion rates were not changed before arteriolar diameter, and aortic pressure and heart rate had returned to within $\pm 5 \%$ of the values before drug administration. Only intravenous doses of vasodilators producing reductions in mean aortic pressure not exceeding $15 \mathrm{mmHg}$ were evaluated. $30 \mathrm{~min}$ were allowed to elapse between the dose-response experiments with the two drugs. In pilot experiments, lower abdominal aortic flow measured electromagnetically in pentobarbitalanesthetized ventilated rabbits did not differ between control $(n=5)$ and cholesterol-fed rabbits $(n=5)$, values averaging $30 \pm 3$ (mean \pm SE) and $31 \pm 2 \mathrm{ml} / \mathrm{min}$, respectively. Accordingly, distal aortic drug deliveries noted above may be estimated to have produced downstream arterial concentrations of $\mathrm{ACH}$ and $\mathrm{NP}$ ranging between 0.1 and 5.0 and 3.0 and $30 \mu \mathrm{M}$.

In other experiments, arterioles were exposed to vasodilators by superfusing the cremaster muscle with Krebs buffer containing increasing concentrations of $\mathrm{ACH}(0.1-100 \mu \mathrm{M})$ or NP $(10-100 \mu \mathrm{M})$. The drugs were administered in randomized sequence, and individual concentrations were given until the monitored arteriolar diameter remained stable for $2 \mathrm{~min}$. The person interpreting video images was blinded with respect to the type of drug administered. Even with the lowest drug concentrations, steady state diameters occurred quickly ( $<1 \mathrm{~min}$ ). Dose-response experiments were repeated after addition to the superfusate of an inhibitor cocktail ( $1 \mu \mathrm{M}$ propanolol, $1 \mu \mathrm{M}$ phentolamine, and $50 \mu \mathrm{M}$ indomethacin) or of reducing (antioxidant) agents known to inactivate EDRF (50 $\mu \mathrm{M}$ hydroquinone, $10 \mu \mathrm{M}$ phenidone) $(10,11)$. The efficacy of the pharmacological blockade was established by demonstrating that microvascular dilator responses to superfusional delivery of $0.1 \mu \mathrm{M}$ isoproterenol or $1 \mu \mathrm{M}$ arachidonic acid and the constrictor responses to $1 \mu \mathrm{M}$ phenylephrine were abolished ( $n=6$ rabbits).

Combined ipsilateral visualization of the femoral artery and cremaster microvessels permitted us to evaluate mechanisms possibly related to vascular hormonal effects or to drug overflow to the systemic circulation (when drugs were administered topically by superfusion). We considered the possibility that arteriolar dilation during intraaortic ACH infusion did not reflect predominantly a direct arteriolar effect, but an indirect (hormonal) effect due to (endothelium-derived) vasoactive substances released from large arteries and acting downstream on the microvasculature. Possible effects due to vascular hormones or drug recirculation were evaluated in a five step protocol: $(i)$ superfusional administration for $3 \mathrm{~min}$ of $10 \mu \mathrm{M} \mathrm{ACH}$ (absent femoral dilation demonstrated negligible $\mathrm{ACH}$ recirculation); (ii) as in $i$, but with 1 $\mu \mathrm{M}$ atropine added to the superfusate (demonstrated that $\mathrm{ACH}$ effect on microvessel was muscarinic); (iii) intraaortic infusion of $\mathrm{ACH}$ (10 $\mu \mathrm{g} / \mathrm{kg} \cdot \mathrm{min}$ ) (demonstrated dilator potency of $\mathrm{ACH}$ on femoral artery); (iv) as in iii, but with the $1 \mu \mathrm{M}$ atropine added to the superfusate (maintained femoral dilation demonstrated negligible escape of atropine into the systemic circulation; in addition, lack of arteriolar dilation demonstrated that dilators possibly released from the upstream 
vasculature did not act on the microvessels); and (v) repeat of $i i i$ during systemic atropinization with $0.1 \mathrm{mg} / \mathrm{kg}$ i.v. (demonstrated that femoral dilation was muscarinic).

Perfusion fixation and structural analysis. At the end of the pharmacological experiments, the iliac arteries were perfused serially under a static pressure of $100 \mathrm{~mm} \mathrm{Hg}$ with the following solutions at $37^{\circ} \mathrm{C}$ : wash solution ( $250 \mathrm{mM}$ sucrose in $20 \mathrm{mM}$ Hepes buffer, $\mathrm{pH} 7.4$ ) for 4 min; silver stain solution ( $15 \mathrm{mM}[0.25 \%] \mathrm{AgNO}_{3}$ in wash solution) for $1 \mathrm{~min}$; and fixation solution $(250 \mathrm{mM}$ [2.5\%] glutaraldehyde in 150 $\mathrm{mM}$ sodium phosphate buffer, $\mathrm{pH}$ 7.4) for $20 \mathrm{~min}$. $1 \mu \mathrm{M}$ papaverin was included in all solutions, a procedure that prevented constrictions developing during fixation and produced improved silver stains. Study of small arterioles by transmission electron microscopy (EM) failed to reveal striking qualitative changes in hypercholesterolemic rabbits, and quantitative evaluation of microvascular endothelial cells (shape, orientation, size, and organellar structure) will require the application of special scanning EM techniques currently under evaluation in our laboratory. Cremaster muscle samples used for light microscopy were immersed in $10 \%$ buffered formalin, dehydrated with alcohol, and embedded in paraffin. Transverse, $6-\mu \mathrm{m}$ thick sections of the muscles for light microscopic examination were stained with hematoxylin and eosin. Aortas of the rabbits were isolated and prepared for staining with Sudan IV and for microscopic examination as previously described $(2,6)$.

Drugs. Grade A chemicals and drugs were all supplied by the Sigma Chemical Co., St. Louis, MO.

Statistical analysis. If not otherwise specified, the significance of the difference between group means were analyzed by $t$ tests. Paired $t$ tests were used for the comparison of sequential mean values in the same group, and unpaired $t$ tests were applied for the comparison of corresponding mean values in different groups. In one dose-response experiment (Fig. 5) the data were partly nonnormally distributed and the $t$ test for paired samples was substituted by Wilcoxon's signed-rank test. Differences were considered significant when $P$ values were $<0.05$.

\section{Results}

Systemic hemodynamics. Heart rate and mean aortic pressure did not differ significantly between control and atherosclerotic rabbits $(P>0.5)$ (Table $I)$. Drugs administered topically by superfusion of the cremaster muscle produced no measurable changes in heart rate or mean aortic pressure in either control or atherosclerotic rabbits. In contrast, intraarterial infusions of ACH $(1.2-10.0 \mu \mathrm{g} / \mathrm{kg} \cdot \mathrm{min})$ or sodium NP $(20-80 \mu \mathrm{g} / \mathrm{kg} \cdot \mathrm{min})$ produced within $1 \mathrm{~min}$ stable, dose-dependent decreases in mean aortic pressure, and with $\mathrm{ACH}$ in doses exceeding 3.0 $\mu \mathrm{g} / \mathrm{kg} \cdot \mathrm{min}$ there were in addition minor decreases in heart rate. The absolute hemodynamic changes were small even at the highest dose levels and did not differ significantly between control and atherosclerotic rabbits (Table I). Heart rate and mean aortic pressure returned within $3 \mathrm{~min}$ or less to baseline after each intraarterial drug challenge, and absolute values at the beginning and end of the experiment did not differ significantly in either group.

Plasma cholesterol. Plasma total cholesterol before killing the rabbits averaged $58 \pm 7 \mathrm{mg} / \mathrm{dl}($ mean $\pm S E)$ in control rabbits $(n=6)$ and $1,758 \pm 281 \mathrm{mg} / \mathrm{dl}$ in cholesterol-fed rabbits $(n=6)$.

Spontaneous fluctuations in arteriolar diameter. The arterioles exhibited rhythmic contractions as reported for other species (12). Contractions decreased the arteriolar diameter maximally by $8-15 \%$ and occurred at a frequency of $8-20 / \mathrm{min}$. The amplitude and frequency of the oscillations were virtually identical in control and atherosclerotic rabbits, values averaging $10 \pm 1 \%$ and $9 \pm 2 / \mathrm{min}$. Arteriolar diameters in this study always refer to values representing the arithmetic mean of the maximal and minimal amplitude of the oscillation. Values for control and atherosclerotic rabbits averaged $26.3 \pm 2.1$ and 28.4 $\pm 2.2 \mu \mathrm{m}(P>0.5)$.

Response to sodium NP. Intraarterial and topical administrations of sodium NP dilated arterioles dose dependently. The dose-response curves for control and atherosclerotic rabbits were virtually identical (Table I; Figs. 1 and 2).

Response to $A C H$. Intraarterial and topical administrations of ACH dilated arterioles dose dependently (Table I; Figs. 1 and 2). The highest intraarterial $(10 \mu \mathrm{g} / \mathrm{kg} \cdot \mathrm{min})$ and topical $(100 \mu \mathrm{M})$ doses dilated the arterioles in control rabbits by

Table I. Hemodynamic and Arteriolar Change by Intraarterial Administration of Drugs

\begin{tabular}{|c|c|c|c|c|c|c|c|c|c|}
\hline & \multicolumn{5}{|c|}{$\mathrm{ACH}(\mu \mathrm{g} / \mathrm{kg} \cdot \min )$} & \multicolumn{4}{|c|}{$\mathrm{NP}(\mu \mathrm{g} / \mathbf{k g} \cdot \min )$} \\
\hline & 0.14 & 0.4 & 1.2 & 3 & 10 & 7 & 20 & 40 & 80 \\
\hline \multicolumn{10}{|c|}{ Control rabbit $(n=10)$} \\
\hline \multicolumn{10}{|c|}{ Aortic pressure $(\mathrm{mmHg})$} \\
\hline Before & $106.2 \pm 2.9$ & $105.3 \pm 5.3$ & $106.4 \pm 6.0$ & $105.7 \pm 5.4$ & $105.8 \pm 4.6$ & $106.2 \pm 4.4$ & $107.3 \pm 4.9$ & $106.8 \pm 4.9$ & $107.4 \pm 6.1$ \\
\hline 2 min after & $106.2 \pm 2.9$ & $105.3 \pm 5.4$ & $102.8 \pm 5.8^{*}$ & $94.7 \pm 4.9 *$ & $93.0 \pm 4.3^{*}$ & $106.3 \pm 4.5$ & $98.3 \pm 6.8^{*}$ & $95.4 \pm 5.0^{*}$ & $95.0 \pm 5.9 *$ \\
\hline \multicolumn{10}{|c|}{ Heart rate (beats/min) } \\
\hline Before & $217 \pm 12$ & $216 \pm 12$ & $223 \pm 11$ & $210 \pm 10$ & $210 \pm 10$ & $211 \pm 13$ & $213 \pm 13$ & $210 \pm 17$ & $214 \pm 15$ \\
\hline $2 \mathrm{~min}$ after & $217 \pm 12$ & $219 \pm 12$ & $224 \pm 12$ & $204 \pm 9^{8}$ & $198 \pm 10^{8}$ & $211 \pm 14$ & $219 \pm 10$ & $214 \pm 13$ & $218 \pm 16$ \\
\hline \multicolumn{10}{|c|}{ Arteriolar diameter $(\mu m)$} \\
\hline Before & $24.5 \pm 1.9$ & $24.6 \pm 1.7$ & $24.5 \pm 1.9$ & $23.8 \pm 1.6$ & $24.1 \pm 1.6$ & $26.0 \pm 3.0$ & $26.4 \pm 4.2$ & $26.8 \pm 2.9$ & $26.9 \pm 2.9$ \\
\hline $2 \mathrm{~min}$ after & $25.5 \pm 2.5$ & $27.9 \pm 2.2^{*}$ & $39.2 \pm 4.4^{*}$ & $46.6 \pm 4.2^{*}$ & $53.5 \pm 4.8^{*}$ & $31.8 \pm 3.6^{*}$ & $37.7 \pm 6.6^{*}$ & $39.4 \pm 4.8^{*}$ & $45.9 \pm 5.4^{*}$ \\
\hline \multicolumn{10}{|c|}{ Atherosclerotic rabbit $(n=6)$} \\
\hline \multicolumn{10}{|c|}{ Aortic pressure $(\mathrm{mmHg})$} \\
\hline Before & $103.5 \pm 5.9$ & $107.7 \pm 2.4$ & $103.4 \pm 5.6$ & $105.5 \pm 5.1$ & $105.0 \pm 5.1$ & $107.3 \pm 1.2$ & $110.7 \pm 3.3$ & $106.0 \pm 3.2$ & $107.4 \pm 3.7$ \\
\hline $2 \mathrm{~min}$ after & $103.5 \pm 5.9$ & $107.6 \pm 2.4$ & $95.9 \pm 4.4^{*}$ & $99.2 \pm 3.4^{*}$ & $94.7 \pm 5.2^{*}$ & $103.9 \pm 2.9$ & $97.2 \pm 4.3^{*}$ & $101.0 \pm 4.1^{*}$ & $95.4 \pm 2.4^{*}$ \\
\hline \multicolumn{10}{|c|}{ Heart rate (beats/min) } \\
\hline Before & $217 \pm 12$ & $214 \pm 10$ & $218 \pm 14$ & $211 \pm 13$ & $212 \pm 12$ & $209 \pm 15$ & $212 \pm 16$ & $215 \pm 14$ & $213 \pm 16$ \\
\hline 2 min after & $229 \pm 14$ & $214 \pm 12$ & $216 \pm 10$ & $202 \pm 8^{5}$ & $194 \pm 10^{5}$ & $211 \pm 17$ & $213 \pm 13$ & $221 \pm 12$ & $220 \pm 17$ \\
\hline \multicolumn{10}{|c|}{ Arteriolar diameter $(\mu \mathrm{m})$} \\
\hline Before & $25.2 \pm 2.6$ & $24.1 \pm 3.0$ & $23.8 \pm 2.7$ & $24.0 \pm 2.0$ & $26.0 \pm 1.4$ & $25.4 \pm 2.4$ & $25.3 \pm 1.9$ & $25.6 \pm 3.6$ & $26.3 \pm 3.4$ \\
\hline 2 min after & $25.8 \pm 2.7$ & $26.3 \pm 4.0^{*}$ & $32.7 \pm 5.6^{*}$ & $34.7 \pm 3.3^{\ddagger 5}$ & $40.1 \pm 4.4^{\ddagger 8}$ & $27.5 \pm 2.0^{*}$ & $34.1 \pm 3.3^{*}$ & $41.0 \pm 6.9^{*}$ & $49.0 \pm 9.9^{*}$ \\
\hline
\end{tabular}

$* P<0.01$ before vs. 2 min after drug injection (paired $t$ test). ${ }^{*} P<0.05$ control vs. atherosclerotic (unpaired $t$ test). $P<0.05$ before vs. 2 min after drug injection (paired $t$ test). 


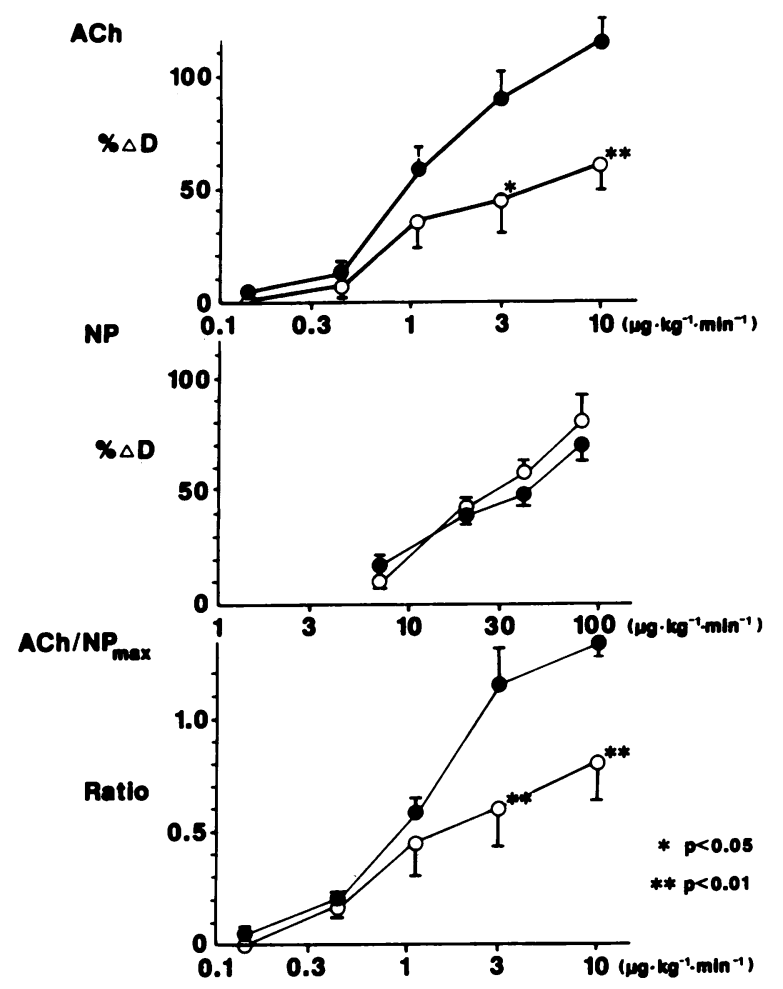

Figure 1. Dose-response relation of arteriolar dilation to intraarterial $\mathrm{ACH}$ or NP. \% $\Delta \mathrm{D}$, Change in arteriolar diameter in this and subsequent figures is expressed as percent increase above value before drug administration. $\mathrm{NP}_{\max }$, Arteriolar dilation with $80 \mu \mathrm{g} / \mathrm{kg} \cdot \min \mathrm{NP}$ intraarterially. Vertical bars in this and subsequent figures indicate 1 SE. $* P<0.05 ; * * P<0.01$ vs. nonatherosclerotic control (unpaired $t$ test). (๑) Control; (O) atherosclerotic.

$116 \pm 11$ and $124 \pm 9 \%$, respectively. A typical response to $1 \mu \mathrm{M}$ $\mathrm{ACH}$ in a control rabbit is shown in Fig. 3. Note that maximal concentrations of $\mathrm{NP}(100 \mu \mathrm{M})$ and $\mathrm{ACH}(10-100 \mu \mathrm{M})$ dilated the arterioles of the control rabbit to a similar extent.

In atherosclerotic rabbits, cholinergic arteriolar dilation was attenuated compared with control rabbits. The differences between the groups were highly significant, with doses exceeding $3.0 \mu \mathrm{g} / \mathrm{kg} \cdot \mathrm{min}$ intraarterially or $0.1 \mu \mathrm{M}$ topically (Table I; Figs. 1 and 2$)$. With the highest doses tested $(10 \mu \mathrm{g} / \mathrm{kg} \cdot \mathrm{min}$ intraarterial or $100 \mu \mathrm{M}$ topical), dilator responses averaged
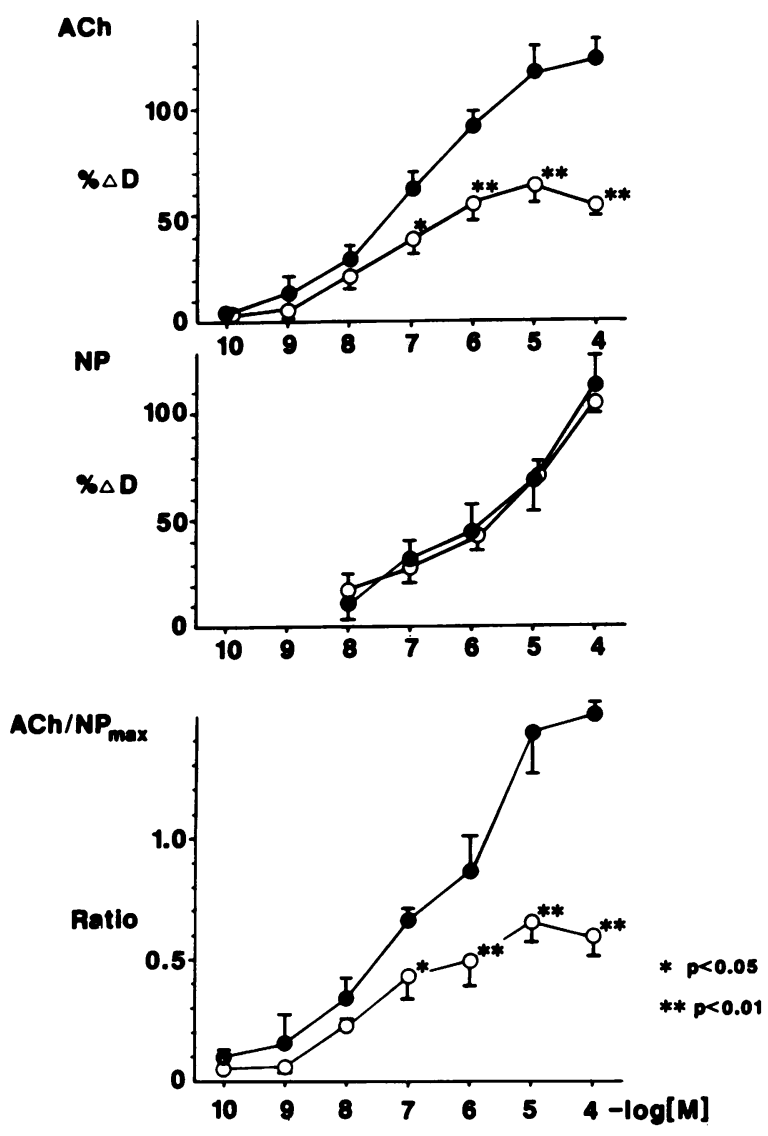

Figure 2. Dose-response relation of arteriolar dilation to topical $\mathrm{ACH}$ or NP. $\mathrm{NP}_{\max }$, Arteriolar dilation with $100 \mu \mathrm{M} \mathrm{NP} . * P<0.05 ; * * P$ $<0.01$ vs. nonatherosclerotic control (unpaired $t$ tests). (๑) Control; (O) atherosclerotic.

$60 \pm 12$ and $54 \pm 4 \%$ in atherosclerotic rabbits compared with $116 \pm 11$ and $124 \pm 9 \%$ in controls $(P<0.01)$.

$\mathrm{ED}_{\mathbf{s}_{0}}$ values for intraarterial or topical $\mathrm{ACH}$ did not differ significantly between control and atherosclerotic rabbits $(1.6 \pm 0.2$ vs. $1.9 \pm 0.7 \mu \mathrm{g} / \mathrm{kg} \cdot \min , P>0.05$; and $190 \pm 98$ vs. $79 \pm 20 \mathrm{nM}, P>0.05)$.

To assess cholinergic responsiveness using each rabbit as its own control, responses to $\mathrm{ACH}$ were expressed with respect to

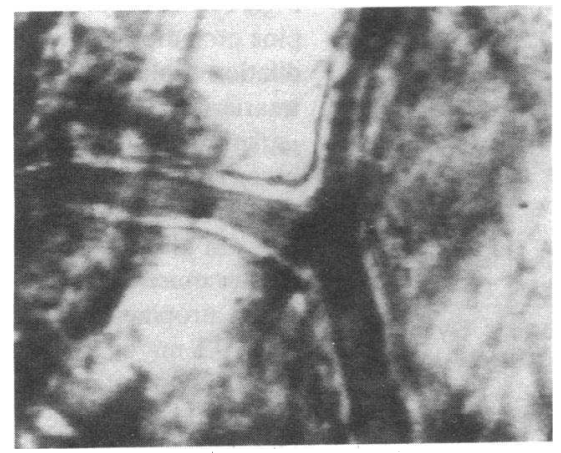

Without ACh

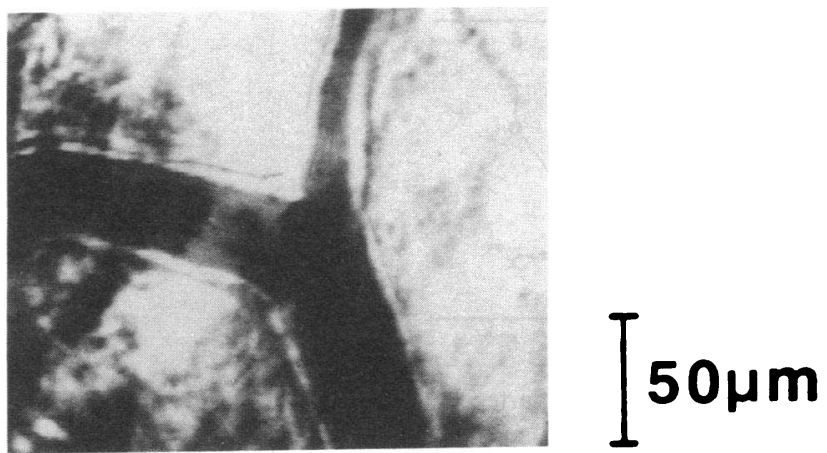

With ACh (1 $\mu \mathrm{M})$

Figure 3. In vivo photograph of third order arteriole of the cremaster muscle in normal rabbit. 
those elicited by the highest dose of NP. Figs. 1 and 2 illustrate the response ratios for intraarterial and topical administrations in the two groups.

Responses after combined blockade with phentolamine, propranolol, and indomethacin. $1 \mu \mathrm{M}$ phentolamine, $1 \mu \mathrm{M}$ propranolol, and $50 \mu \mathrm{M}$ indomethacin were included in the buffer superfusing the cremaster muscle to effect a blockade of adrenergic receptors $\left(\alpha_{1,2}, \beta_{1,2}\right)$ and cycloxygenase activity. The combined blockade increased the mean arteriolar diameter from $28.4 \pm 3.4$ to $31.7 \pm 3.3 \mu \mathrm{m}(P>0.5)$ in controls and from $29.2 \pm 3.1$ to $30.6 \pm 3.1 \mu \mathrm{m}(P>0.5)$ in atherosclerotic rabbits $(P>0.5)$. The blockade did not alter the dilation in response to topical NP in either control or atherosclerotic rabbits. The blockade slightly reduced the responses to ACH in both control and atherosclerotic rabbits, but the substantial difference in muscarinic responsiveness between the two groups persisted (Fig. 4). The cholinergic impairment in atherosclerotic rabbits was also expressed in a reduced $\mathrm{ACH}$ to NP response ratio (Fig. 4).

Responses after blockade with phenidone or hydroquinone. Fig. $5 A$ shows that phenidone significantly suppressed the arteriolar dilation in response to $\mathrm{ACH}$ without however influencing those to NP. A very similar blockade of the endothelium-dependent agent without change in response to the endothelium-independent agent was observed with hydroquinone (Fig. $5 \mathrm{~B}$ ). Time control experiments ( $n=4$ rabbits) involving two sequential muscarinic stimulations without inhibitor demonstrated that repeat responses did not differ significantly from initial responses.

Effect of atropine. Intraarterial administration of ACH (10 $\mu \mathrm{g} / \mathrm{kg} \cdot \mathrm{min})$ dilated the femoral artery by $74.6 \pm 12.7 \%$, but 10

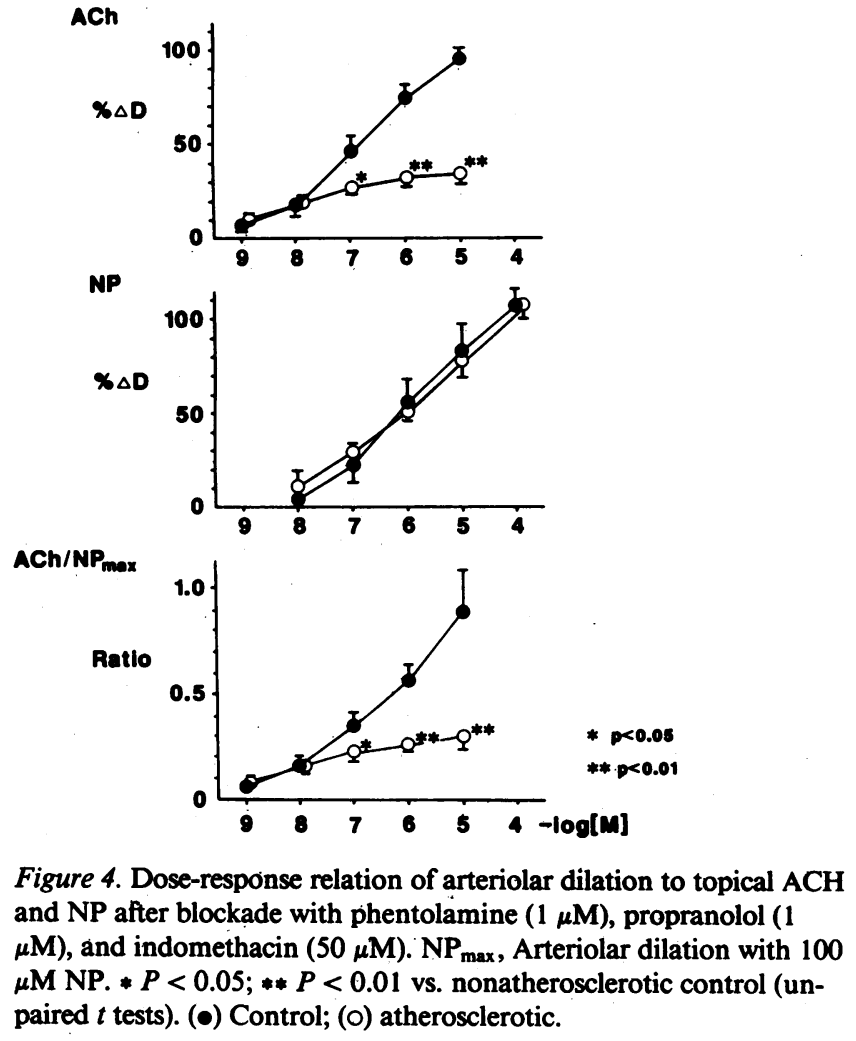

\section{A Phenidone}

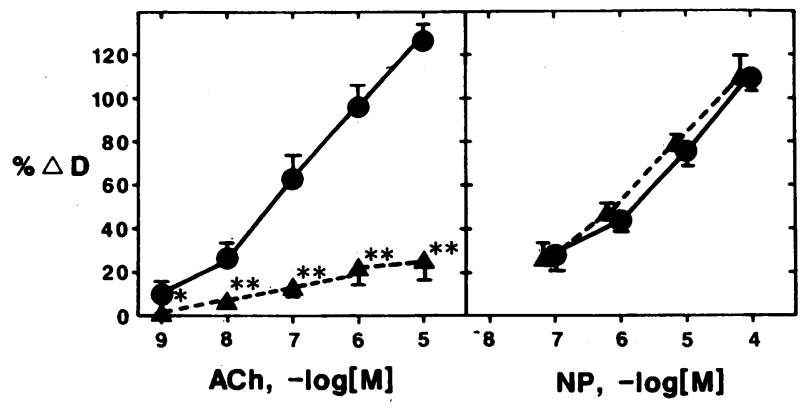

B Hydroquinone

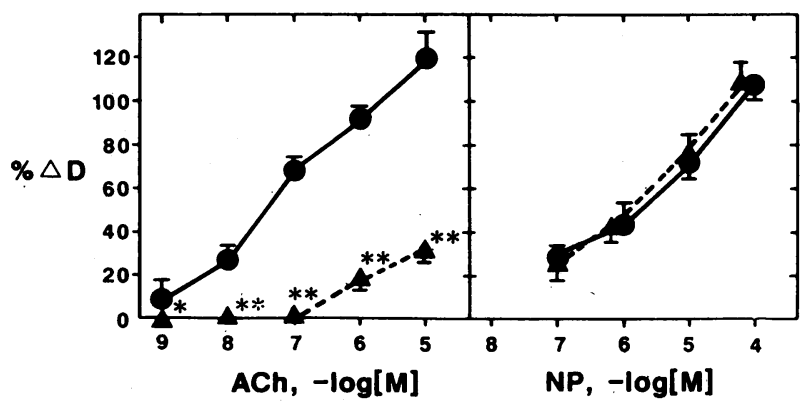

Figure 5. Drug concentration/diameter relations before (circles) and after (triangles) treatment with $10 \mu \mathrm{M}$ phenidone $(A)$ or $50 \mu \mathrm{M}$ hydroquinone $(B)$. The antioxidizing agents suppress the responses to ACH but not NP. $* P<0.05 ; * * P<0.01$ before vs. after treatment (Wilcoxon's signed-rank test).

$\mu \mathrm{M}$ ACH given topically by superfusion had no influence on the femoral diameter (Fig, 6). $1 \mu \mathrm{M}$ atropine in the buffer superfusing the cremaster muscle completely or nearly completely inhibited the arteriolar dilation to both topical $(10 \mu \mathrm{M})$ and intraarterial $(10 \mu \mathrm{g} / \mathrm{kg} \cdot \mathrm{min}) \mathrm{ACH}$ (Fig. 7). Atropine in the superfusate had no influence on femoral dilation in response to intraarterial ACH $(10 \mu \mathrm{g} / \mathrm{kg} \cdot \min )(77.7 \pm 11.0 \%, P>0.05$ vs. before atropine). However, systemic muscarinic blockade $(0.1 \mathrm{mg} / \mathrm{kg}$ atropine i.v.) completely blocked the femoral as well as the arteriolar responses (Figs. 6 and 7).

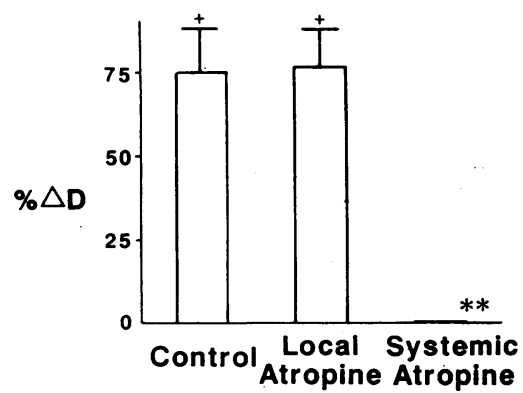

Figure 6. Effect of atropine on femoral artery dilation evoked by intraarterial ACH, 10 $\mu \mathrm{g} / \mathrm{kg} \cdot \mathrm{min}$. Local atropine, Topical (superfusional) administration of $1 \mu \mathrm{M}$ atropine to cremaster muscle. Systemic atropine, Atropine, $0.1 \mathrm{mg} / \mathrm{kg}$ i.v. Resting femoral diameter did not differ between groups, values for control, local atropine, and systemic atropine averaging $1.0 \pm 0.1,1.0 \pm 0.2$, and $0.9 \pm 0.1 \mathrm{~mm}$. ** $P<0.01$ vs. control before systemic atropine (paired $t$ test); $+P<$ 0.01 vs. before ACH administration (paired $t$ tests). 


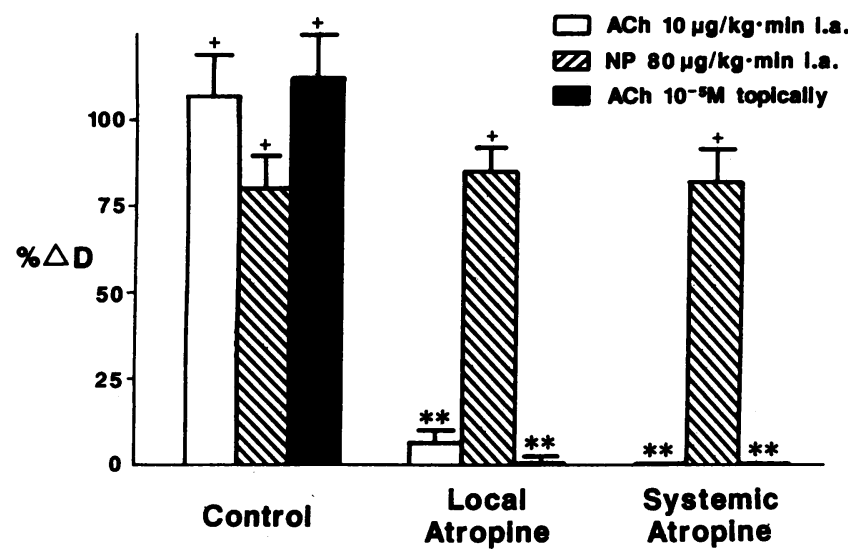

Figure 7. Effect of atropine on arteriolar response to ACH and NP. $\mathrm{ACH}$ was administered intraarterially $(10 \mu \mathrm{g} / \mathrm{kg} \cdot \mathrm{min})$ or topically $(10 \mu \mathrm{M})$, and NP intraarterially $(80 \mu \mathrm{g} / \mathrm{kg} \cdot \mathrm{min})$. Resting diameter of control before intraarterial $\mathrm{ACH}$ was $31.4 \pm 2.9 \mu \mathrm{m}$. Resting arteriolar diameter did not differ significantly between groups. $* * P<0.01$ vs. control before atropine (paired $t$ tests); $+P<0.01$ vs. before vasodilator administration (paired $t$ tests). Local and systemic atropine, see legend to Fig. 6.

Gross and microscopic morphology. Aortas from control rabbits $(n=6)$ showed no sudanophilic lesions. In cholesterolfed rabbits $(n=6)$, the percent of intimal area of the thoracic aorta occupied by sudanophilic lesions averaged $48 \pm 7 \%$, a value close to that reported in our previous studies $(2,4)$.

Stained transverse sections of cremaster muscles from six control and six cholesterol-fed rabbits were studied by light microscopy. Focusing on arterioles over a wide range of internal diameters $(20-200 \mu \mathrm{m})$ revealed no consistent difference between control and hypercholesterolemic rabbits. The endothelial cell lining appeared intact and appreciable thickening of the arteriolar walls was not demonstrable. Abnormal accumulation of cells including lymphocytes, plasma cells, and mast cells were not observed. There were, however, occasional foam cells in the interstitial space surrounding the arterioles. EM studies are in progress to determine whether cholesterol-fed rabbits exhibit consistent ultrastructural arteriolar alterations.

\section{Discussion}

Previous experiments with cholesterol-fed rabbits in our laboratory have shown that $\mathrm{ACH}$ produces limited reductions in hindlimb total vascular resistance, whereas NP is equally potent in cholesterol-fed and control rabbits (5). Since changes in total vascular resistance are determined to a large extent by the tone of small arteries and arterioles, we postulated that cholesterol-fed rabbits may have a defective microvascular regulation. The results of this study demonstrate directly that arteriolar regulation is impaired in cholesterol-fed rabbits. To characterize the arteriolar defect we have tested substances previously shown to interfere with endothelium-dependent relaxation of large arteries in vitro $(9,10)$. Unfortunately, selective blocking agents of EDRF are not available. Nevertheless, with two reducing agents, phenidone and hydroquinone, we were able to suppress the relaxation to $\mathrm{ACH}$, an endothelium-dependent agent, without reducing the potency of NP, an endotheliumindependent agent $(10,11,13)$. Therefore, we tentatively con- clude that the arteriolar defect in the present experiments is similar in nature to the endothelium-dependent defect demonstrable in large atherosclerotic arteries from rabbits and other species (2-4). Since impaired arteriolar vasodilation occurred only with $\mathrm{ACH}$, but not with NP, it appears unlikely that the defect was related to some structural alteration preventing arteriolar dilation. After regional muscarinic blockade of the cremaster microvessels, intraaortic infusion of $\mathrm{ACH}$ dilated the femoral artery but had only a small effect on the cremaster vessels. This demonstrates that EDRF released from large vessels had little effect on the regional microvasculature. When $\mathrm{ACH}$ was administered topically, there were no systemic hemodynamic changes and no macrovascular (femoral) dilation demonstrable. This indicates that there was no appreciable overflow of $\mathrm{ACH}$ from the cremaster circulation into the systemic circulation. In combination, these observations indicate that altered responses of arterioles to ACH represented an intrinsic arteriolar alteration and not an indirect hemodynamic or vascular hormonal effect.

Our light microscopic studies (and preliminary EM findings not reported here) have thus far failed to reveal any striking structural change of arterioles of the cremaster muscle in cholesterol-fed rabbits. The lack of arteriolar changes in cholesterol-fed rabbits with severe atherosclerosis of the large vessels has been previously emphasized (14). In aortas of cholesterol-fed rabbits, changes in the size and orientation of endothelial cells have a complex topology. Although these changes are readily apparent on low magnification scanning EM, they may easily remain undetected on routine light microscopic and transmission electromicroscopic examination (15). In this context, it should be noted that changes in endothelial structure occurring in rabbit aorta with abnormal endothelial permeability (15) or defective endothelium-dependent relaxation (2) have nothing to do with atherosclerotic endothelial desquamation. Similarily, human coronary arteries with intact endothelial cell lining may exhibit striking defects in endothelium-mediated relaxation in vitro (4). Therefore, before making definitive statements about arteriolar structure in the presence of macrovascular atherosclerosis, appropriate stereologic and scanning EM techniques will have to be developed and applied.

In this study, we have focussed on endothelium-dependent vasomotor effects. It should be stressed that altered arterial reactivity in animals with experimental atherosclerosis and in man is not related exclusively to an abnormality of endothelially mediated vasoregulation, but reflects in part intrinsic alterations of arterial smooth muscle. For instance, the atherrosclerotic supersensitivity to serotonin in rabbits and pigs reflects intrinsic changes in smooth muscle that persist after mechanical removal of endothelium and/or adventitia (16-18).

For many years, clinicians have been intrigued by the fact that in some patients with electrocardiographic, scintigraphic, and biochemical signs of myocardial ischemia the coronary arteriogram fails to reveal occlusive or spastic disease of the epicardial coronary arteries. Therefore, myocardial ischemia in these patients has been tentatively ascribed to a defect affecting small arteries not visualized by arteriography (19). The findings of the present study demonstrating for the first time a hypercholesterolemic microvascular defect are compatible with the notion that dynamic microvascular factors might play a role in determining episodes of ischemia. 


\section{Acknowledgments}

The authors gratefully acknowledge the excellent assistance of Winifred $\mathrm{K}$. Boyce in the preparation of this manuscript.

This work was supported in part by grants from National Institutes of Health (HL-31487 and HL-36894).

\section{References}

1. Ross, R. 1986. The pathogenesis of atherosclerosis: an update. $N$. Engl. J. Med. 314:488-500.

2. Habib, J. B., C. Bossaller, S. Wells, C. Williams, J. D. Morrisett, and P. D. Henry. 1986. Preservation of endothelium-dependent vascular relaxation in cholesterol-fed rabbit by treatment with the calcium blocker PN 200110. Circ. Res. 58:305-309.

3. Freiman, P. C., G. C. Mitchell, D. D. Heistad, M. L. Armstrong, and D. G. Harrison. 1986. Atherosclerosis impairs endothelium-dependent yascular relaxation to acetylcholine and thrombin in primates. Circ. Res. 58:783-789.

4. Bossaller, C., G. B. Habib, H. Yamamoto, C. Williams, S. Wells, and P. D. Henry. 1987. Impaired muscarinic endothelium-dependent relaxation and cyclic guanosine 5'-monophosphate formation in atherosclerotic human coronary artery and rabbit aorta. J. Clin. Invest. 79:170-174.

5. Bossaller, C., H. Yamamoto, and P. D. Henry. 1986. Demonstration of impaired cholinergic vasodilation of atherosclerotic rabbit in vivo. J. Am. Coll. Cardiol. 7:53A. (Abstr.)

6. Henry, P. D., and K. I. Bentley. 1981. Suppression of atherogenesis in cholesterol-fed rabbit treated with nifedipine. J. Clin. Invest. 68:1366-1369.

7. Baez, S. 1973. An open cremaster muscle preparation for the study of blood vessels by in vivo microscopy. Microvascular Research 5:384-394.

8. Proctor, K. G., D. N. Damon, B. R. Duling. 1984. Inaccuracies in blood flow estimates in microvessels during arteriolar vasoconstriction. Microvasc. Res. 28:23-36.
9. Bossaller, C., H. Yamamoto, P. R. Lichtlen, and P. D. Henry, 1987. Impaired cholinergic vasodilation in the cholesterol-fed rabbit in vivo. Basic Res. Cardiol. 82:396-404.

10. Griffith, T. M., A. H. Henderson, D. Hughes Edwards, and M. J. Lewis. 1984. Isolated perfused rabbit coronary artery and aortic strip preparations: the role of endothelium-derived relaxant factor. $J$. Physiol. 351:13-24.

11. Rubanyi, G. M., and P. M. Vanhoutte. 1986. Superoxide anions and hyperoxia inactive endothelium-derived relaxing factor. Am. J. Physiol. 250(Heart Circ. Physiol. 19):H822-H827.

12. Colantuoni, A., S. Bertuglia, and M. Intaglietta. 1984. Quantitation of rhythmic diameter changes in arterial microcirculation. Am. J. Physiol. 246(Heart Circ. Physiol. 15):H508-H517.

13. Furchgott, R. F., P. D. Cherry, J. V. Zawadzki, and D. Jothianandan. 1984. Endothelial cells as mediators of vasodilation of arteries. J. Cardiovasc. Pharmacol. 6 (Suppl. 2):S336-S343.

14. Chan, C. T., P. Brecher, C. Haudenschild, and A. V. Chobanian. 1979. The effect of cholesterol feeding on the metabolism of rabbit cerebral microvessels. Microvasc. Res. 18:353-369.

15. Stemerman, M. B. 1981. Effects of moderate hypercholesterolemia on rabbit endothelium. Arteriosclerosis. 1:25-32.

16. Henry, P. D., and M. Yokoyama. 1980. Supersensitivity of atherosclerotic rabbit aorta to ergonovine. Mediation by a serotonergic mechanism. J. Clin. Invest. 66:306-313.

17. Verbeuren, T. J., F. H. Jordaens, L. L. Zonnekeyn, C. E. Van Hove, M. C. Coene, and A. G. Herman. 1986. Effect of hypercholesterolemia on vascular reactivity in the rabbit. I. Endothelium-dependent and endothelium-independent contractions and relaxations in isolated arteries of control and hypercholesterolemic rabbits. Circ. Res. 58:552-564.

18. Prince, C. R., M. V. Tantengco, R. Virmani, R. T. Light, G. C. Friesinger, and $R$. M. Robertson. 1987. In vivo and in vitro coronary vascular reactivity in hyperlipidemic swine. J. Am. Coll. Cardiol. 9:210A. (Abstr.)

19. Cannon, R. O., III, W. H. Schenke, M. B. Leon, D. R. Rosing, J. Urqhart, and S. E. Epstein. 1987. Limited coronary flow reserve after dipyridamole in patients with ergonovine-induced coronary vasoconstriction. Circulation. 75:163-174. 